\title{
Effects of climate and land use change on groundwater depth in Sanjiang Plain
}

\author{
Xiangyi Ding ${ }^{1,2, a}$, Bo Zhang ${ }^{1,2, b}$ and Jiahong Liu ${ }^{1,2, c, *}$ \\ ${ }^{1}$ State Key Laboratory of Simulation and Regulation of the River Basin Water Cycle, China Institute of \\ Water Resources and Hydropower Research (IWHR), 1 Yu-Yuan-Tan South Road, Beijing, China \\ ${ }^{2}$ Department of Water Resources, China Institute of Water Resources and Hydropower Research (IWHR), 1 \\ Yu-Yuan-Tan South Road, Beijing, China \\ a dingxiangyi840318@163.com, ${ }^{\text {b } 786493581 @ q q . c o m, ~}{ }^{\mathrm{c}}$ liujiahong00@sohu.com \\ *corresponding author
}

Keywords: Groundwater depth; Precipitation; Land use change; Sanjiang Plain

\begin{abstract}
Based on the groundwater depth and precipitation data from 2000-2014 as well as the land use data in 2000 and 2014, this study analyzed the influence of precipitation and land use change on groundwater depth in the Sanjiang plain using correlation analysis and regression analysis methods. The results indicated that: (1) the groundwater depth in the plain significantly increased with an increase rate of $0.15 \mathrm{~m} /$ year; (2) the response of groundwater depth to precipitation had a lag effect with a lag time of $4 \sim 6$ months, and precipitation in November was the major factor affecting the groundwater depth; (3) there were obvious interconversions between different land use types in Sanjiang Plain resulting in the changes of groundwater depth, especially the interconversion between paddy field and dry land.
\end{abstract}

\section{Introduction}

As an important part of hydrological cycle, the groundwater system plays a significant role in ecology, resources and environment [1,2,3,4]. Groundwater depth is a reflection of groundwater system to external factors, as well as an important means to know the change of groundwater and the influence of human activities on the groundwater system [5,6]. Groundwater system is affected by climate change and human activities. In recent years, many scholars have done a lot of research work in terms of groundwater system change and its response to precipitation or land use change individually $[7,8,9]$. This study differs by analyzing the influence of precipitation and land use change on the groundwater depth in the Sanjiang plain, using correlation analysis and regression analysis methods based on the groundwater depth data from 2000 to 2014 as well as precipitation and land use data. The results may contribute to reveal the change rule of groundwater depth in the Sanjiang plain, explore the response characteristics of groundwater depth to precipitation and land use change, thus provide scientific basis and decision support for regional ecological environment protection.

\section{Materials and Methods}

\subsection{Overview of the Study Area}

Sanjiang plain is located in the northeast of Heilongjiang province of China, including the confluence triangle of Heilongjiang river, Songhua river and the Ussuri river, Bonobo Ken river plain and Xingkai lake plain. The region has an area of $105700 \mathrm{~km}^{2}$, accounting for $23 \%$ of the whole province, and involves 7 cities, such as Hegang(HG)、Jiamusi(JMS)、Shangyashan(SYS)、 Haerbin(HEB)、Qitaihe(QTH)、Jixi(JX)、Mudanjiang(MDJ). The geographical location of the study area is shown in Figure 1. Sanjiang plain belongs to the temperate continental monsoon climate zone, summers are hot and rainy affected by Marine warm water mass, while winters are clod and dry affected by Siberian cold wave. The annual average precipitation ranges from 450mm 
to $650 \mathrm{~mm}$, and precipitation mainly concentrates in June-September, and accounts for $70 \%$ of the annual amount. The inter-annual variability of precipitation is large, precipitation in wet year is about $900 \mathrm{~mm}$, while in dry year is only about $300 \mathrm{~mm}$. As an important commodity grain production base and the largest freshwater marsh wetland area in China, Sanjiang plain plays a significance role in ensuring national food security and protecting regional ecology. In recent years, due to climate change and large-scale agricultural development, groundwater depth in the Sanjiang plain has been continuously increasing. As one of the key factors influencing the wetland status, groundwater is vital to wetland conservation. Therefore, it is necessary and of great significance to study the change rule of groundwater depth in Sanjiang plain and its response to precipitation and land use change.

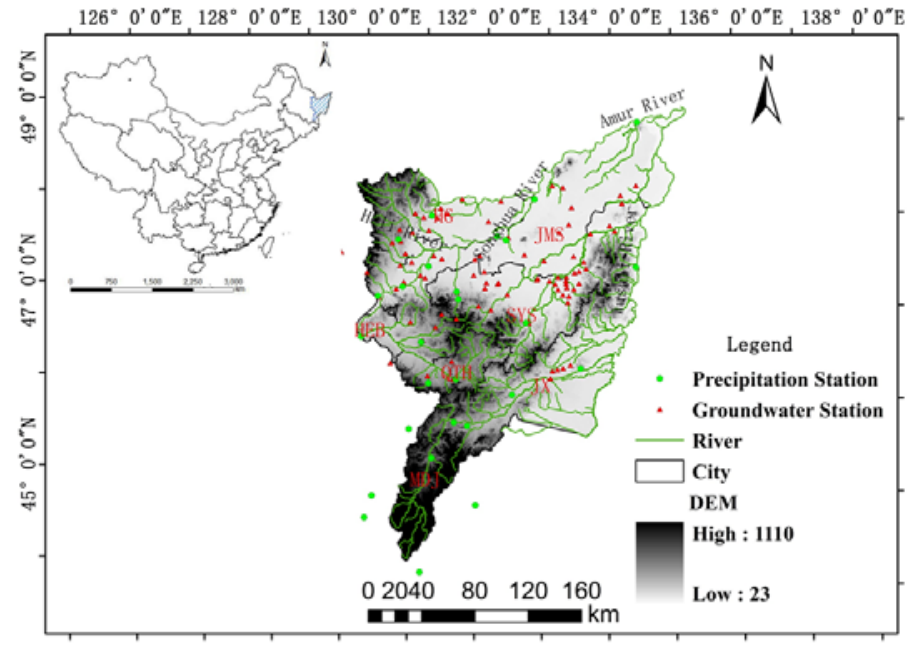

Figure 1 The geographical location of Sanjiang Plain

\subsection{Methodology}

\subsubsection{Data sources and pretreatment}

The groundwater depth data used in this study were from 93 long-term groundwater observation wells in the scope of Sanjiang plain during 2000 2014 with an observation frequency of 5 days. The precipitation data were from the daily rainfall data at 28 stations inside and around the Sanjiang plain. According to the latitude and longitude information of groundwater observation Wells and precipitation stations, groundwater depth and precipitation data of the plain can be obtained using Kriging interpolation method.

Land use data used in this study were from the two phase land use data interpreted by remote sensing in 2000 and 2014, which included 7 kinds of land use types, i.e., paddy field, dry land, forest land, grassland, water area and unused land (including saline-alkali land, wetland, bare land, etc.) as well as resident land. The area of different land use types in 2000 and 2014 can be obtained through statistics.

\subsubsection{Analysis method}

Correlation analysis method was used to analyze the lag of groundwater depth to precipitation, and stepwise regression analysis method was further used to analyze the response of groundwater depth to precipitation. Stepwise regression analysis is a kind of method which can pick out the most significant variable from several independent variables. Based on the importance of independent variable's influence on the dependent variable, this method turns into the regression equation one by one, weeds out non-significant variables due to the introduction of new variables, proceeds step by step repeatedly until there is no significant variable to introduce and there is no non-significant variable in the regression equation [10]. In order to ensure that only significant variables exist in the regression equation before introducing new variables, $\mathrm{F}$ value test is needed. $\mathrm{F}$ value can be calculated using the Formula 1. 


$$
F_{i}=V_{i}\left(x_{1}, x_{2}, \ldots, x_{l}\right) /\left[S S_{S}\left(x_{1}, x_{2}, \ldots, x_{l}, x_{i}\right) /(n-l-2)\right]
$$

where $F_{i}$ is the $\mathrm{F}$ value for step $i ; V_{i}\left(x_{1}, x_{2}, \ldots, x_{l}\right)$ is the contribution of added independent variable $x_{i}$ to the sum of regression squares; $S S_{s}\left(x_{1}, x_{2}, \ldots, x_{l}, x_{i}\right)$ is sum of squared residuals after adding the independent variable $x_{i} ; n$ is sample size; $l$ is the number of introduced variables. Whether the independent variable $x_{i}$ should be introduced or removed is determined by comparing the value of $F_{i}$ with the critical test values.

In this study, transfer matrix of each land use type from 2000 to 2014 was firstly obtained through matrix operations. On the basis, the response of groundwater depth to land use change was analyzed combining with the spatial changes of groundwater depth during 2000-2014.

\section{Results and Discussions}

\subsection{Spatial and temporal variations of groundwater depth in Sanjiang plain}

The spatial distribution of groundwater depth gradient from 2000 to 2014 in Sanjiang plain was shown in Figure 2. As can be seen, groundwater depth gradients in most of the Sanjiang plain area were increasing, the area with reduced groundwater depth gradient mainly distributed in the central part of Sanjiang plain, such as the northeast HG, the central of JMS, and the eastern of SYS and the northern of SYS.

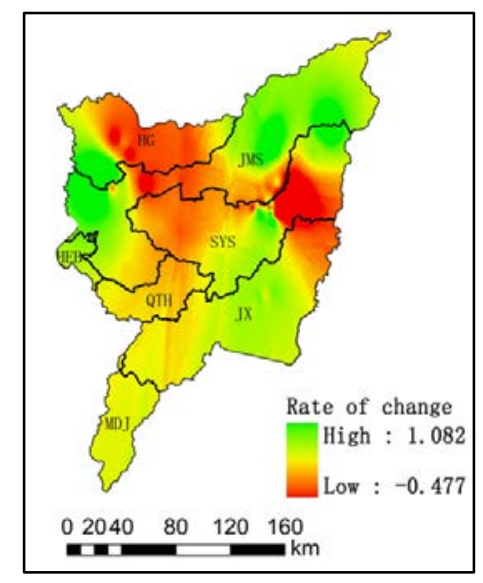

Figure 2 Spatial distribution of groundwater depth gradient from 2000 to 2014 in Sanjiang plain

The temporal variation of groundwater depth from 2000 to 2014 in Sanjiang plain was shown in Figure 3. As can be seen, the groundwater depth increased significantly and passed through the significance test $(\mathrm{P}<0.01)$. The average increase rate was about $0.15 \mathrm{~m} /$ year, and the maximum groundwater depth was $6.7 \mathrm{~m}$ in 2012, the minimum groundwater depth was $4.57 \mathrm{~m}$ in 2000 .

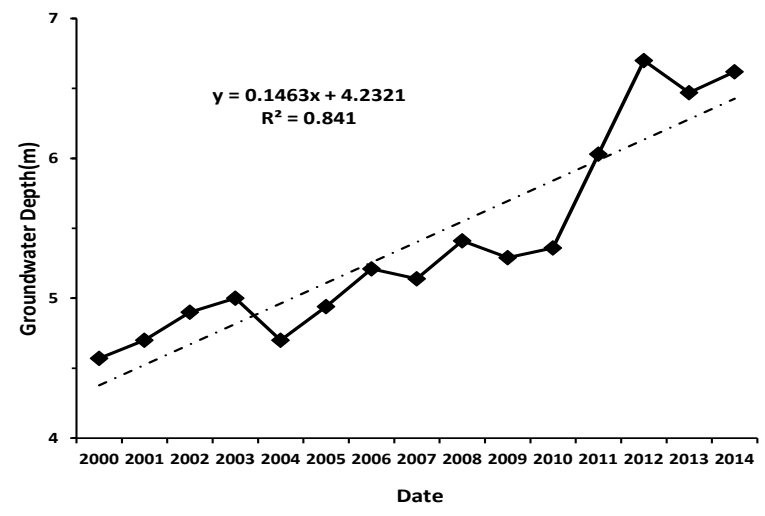

Figure 3 Temporal variation of groundwater depth from 2000 to 2014 in Sanjiang plain 


\subsection{The response of groundwater depth to precipitation}

Precipitation is one of the main factors resulting in the groundwater depth change. The relationship between monthly groundwater depth and precipitation in the same period from 2000 to 2014 was shown in Figure 4. As can be seen, the occurrence time of the peak and valley of groundwater depth was all lag and not consistent with the month of maximum and minimum of precipitation. The groundwater depth did not reduce rapidly after the maximum precipitation, but reached the valley value after 1 6 months. To further analyze the lag time of the response of groundwater depth to precipitation, the groundwater depth data were firstly processed 1 8 months ahead, and then used to conduct correlation analysis respectively with the original precipitation series. The results were shown in Table 1.

As the increase of precipitation, groundwater recharge will increase, groundwater depth will decrease, and thus there was a negative correlation between precipitation and groundwater depth if the time series of groundwater depth was advanced. As can be seen from Table 1, the correlation was most significant and passed the significance test $(\mathrm{P}<0.01)$ when groundwater depth data was advanced for 4 moths, 5 months and 6 months. Therefore, the lag time of the response of groundwater depth to precipitation in the Sanjiang plain was about $4 \sim 6$ months.

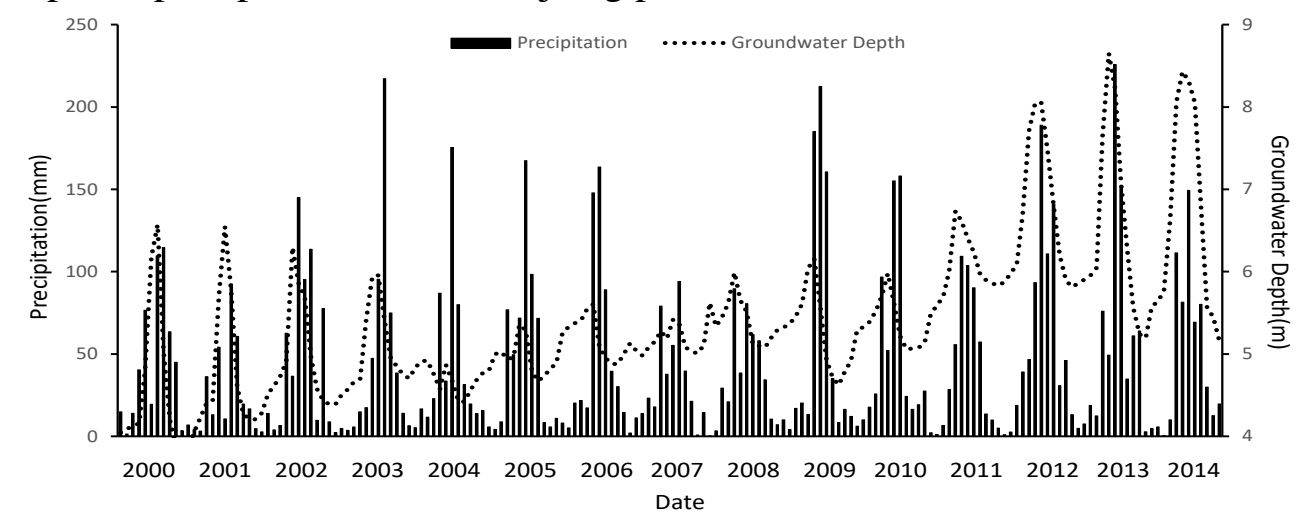

Figure 4 Relationship between monthly groundwater depth and precipitation in the same period

Table 1 Correlation coefficients between the series of precipitation and groundwater depth

\begin{tabular}{ccccccccc}
\hline \multirow{2}{*}{ Item } & \multicolumn{7}{c}{ Advanced time (month) } \\
\cline { 2 - 8 } & 1 & 2 & 3 & 4 & 5 & 6 & 7 & 8 \\
\hline Correlation coefficient & 0.173 & -0.023 & $-0.191^{*}$ & $-0.285^{* *}$ & $-0.279 * *$ & $-0.194^{* *}$ & -0.09 & 0.054 \\
\hline
\end{tabular}

Note: *and** represent the correlation was statistically significant at the confidence level of 0.05 and 0.01 , respectively

In order to further analyze the response of groundwater depth to precipitation, the stepwise regression model was established, with annual precipitation from 2000 to 2014( $\left.\mathrm{x}_{1}\right)$ and monthly precipitation from January to December $\left(\mathrm{x}_{2} \sim \mathrm{x}_{13}\right)$ as the independent variables, and annual groundwater depth as the dependent variable. The model analysis results were shown in Table 2 .

Table 2 Result of stepwise regression model analysis

\begin{tabular}{ccc}
\hline Regression equation & Correlation coefficient & Significance level \\
\hline $\mathrm{Y}=16.17 x_{12}-71.07$ & 0.68 & $\leq 0.01$
\end{tabular}

As can be seen from Table 2, there was only one independent variable $\mathrm{x}_{12}$ (the precipitation of November) entered into the regression equation with a correlation coefficient of 0.68 , and the regression equation was statistically significant at the confidence level of 0.01 . Therefore, the precipitation in November was the main factor affecting groundwater depth in Sanjiang plain. 


\subsection{The response of groundwater depth to land use change}

There was an obvious interconversion among different land use types affected by human activities in Sanjiang plain. Based on the two phase land use data in the area interpreted by remote sensing in 2000 and 2014 as shown in Figure 5a and Figure 5b, the proportion of paddy field increased obviously and dry land decreased significantly, and there was mutual transformation between paddy field and dry land. The proportion of different land use types in 2000 and 2014 was shown in Figure 5c. As can be seen, main land use types in Sanjiang plain were paddy field, dry land and forest land. The sum area of paddy field and dry land accounted for $50 \%$ of the total area, and the proportion of dry land proportion was bigger than paddy field. During the period of 2000-2014, the area of paddy field showed a significant increase trend, and the proportion of paddy field increased from $10.05 \%$ to $17.19 \%$. The area of dry land showed a significant decrease trend, and the proportion of dry land decreased from $39.29 \%$ to $33.65 \%$. The area of residents land showed a significant increase trend, and the proportion of residents land increased from $1.08 \%$ to $2.2 \%$. There was no significant change in the proportion of other land use types.

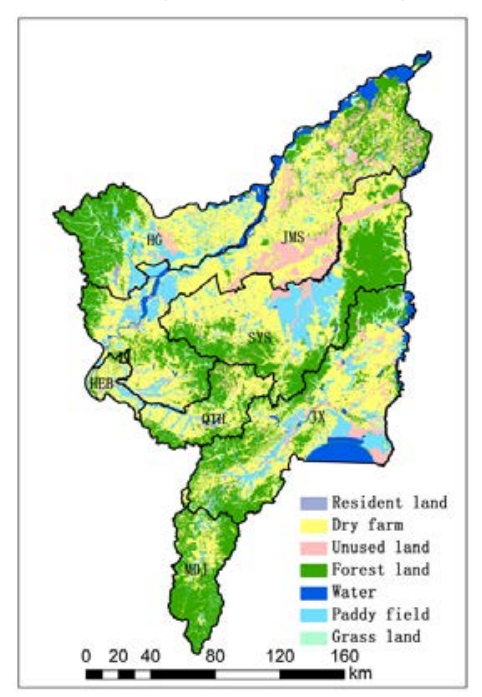

Figure 5(a) Distribution of different land use types in 2000

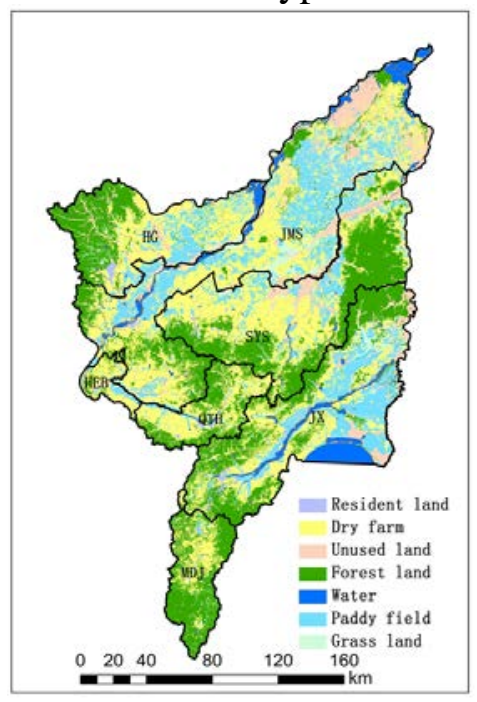

Figure 5(b) Distribution of land use types in 2014

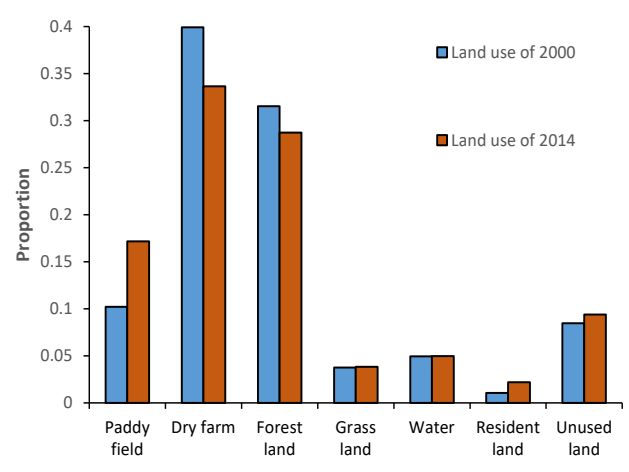

Figure 5(c) Proportion of different land use types in 2000 and 2014 
Table 3 The transfer matrix of land use types during 2000-2014 $\left(\mathrm{km}^{2}\right)$

\begin{tabular}{ccccccccc}
\hline Area & $\begin{array}{c}\text { Grass } \\
\text { land }\end{array}$ & \multicolumn{2}{c}{ Resident land Dry farmForest land Paddy field } & Water & $\begin{array}{c}\text { Unused } \\
\text { land }\end{array}$ & $\begin{array}{c}\text { Total of } \\
\mathbf{2 0 0 0}\end{array}$ \\
\hline Grass land & 577 & 46 & 619 & 1189 & 312 & 153 & 1051 & 3947 \\
Resident land & 14 & 1459 & 400 & 36 & 102 & 17 & 15 & 2043 \\
Dry farm & 1072 & 579 & 25600 & 1728 & 9600 & 642 & 1291 & 40512 \\
Forest land & 744 & 64 & 0 & 28725 & 630 & 360 & 1492 & 32015 \\
Paddy field & 201 & 105 & 3438 & 96 & 5872 & 90 & 562 & 10364 \\
Water & 298 & 10 & 124 & 91 & 55 & 3456 & 1069 & 5103 \\
Unused land & 1048 & 11 & 1597 & 228 & 1158 & 434 & 4207 & 8683 \\
Total of 2014 & 3954 & 2274 & 31778 & 32093 & 17729 & 5152 & 9687 & 102667 \\
\hline
\end{tabular}

The spatial distribution of groundwater depth change in Sanjiang plain during 2000 2014 was shown in Figure 6. As can be seen from Figure 5 and the land use transfer matrix (Table3), there was an obvious transformation between different land use types in Sanjiang Plain and resulting in the changes of groundwater depth. The area with reduced groundwater depth mainly distributed in the east of HG, the center of JMS and the east of SYS, the reduction ranged from 0 to $6 \mathrm{~m}$. From the view of land use change, land use mainly transformed from paddy field to dry land in the east of HG and the east of SYS. The area with increased groundwater depth mainly distributed in the north of JMS, south of SYS and central of JX, the increase ranged from 0 to $10 \mathrm{~m}$. From the view of land use change, land use mainly transformed from dry land to paddy field in these regions. The increase of paddy field led to the increase of groundwater extraction, and then destroyed the balance of groundwater system, finally resulted in the increase of groundwater depth.

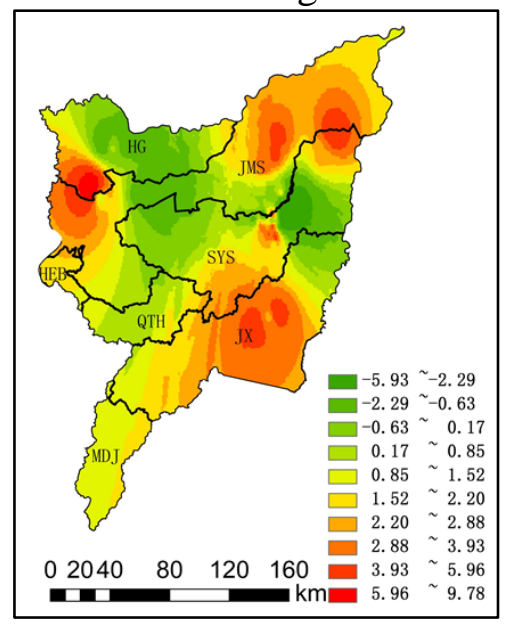

Figure 6 Spatial distribution of groundwater depth change in Sanjiang plain during 2000 to 2014

\section{Conclusions}

Based on the groundwater depth and precipitation data from 2000 to 2014 as well as the land use data in 2000 and 2014, this study analyzed the influence of precipitation and land use change on groundwater depth in the Sanjiang plain using correlation analysis and regression analysis methods. The results indicated that: (1) the groundwater depth in the plain significantly increased with an increase rate of $0.15 \mathrm{~m} /$ year; (2) the response of groundwater depth to precipitation had a lag effect with a lag time of $4 \sim 6$ months, and precipitation in November was the major factor affecting the groundwater depth; (3) there were obvious interconversions between different land use types in Sanjiang Plain resulting in the changes of groundwater depth, especially the interconversion between paddy field and dry land. 


\section{Acknowledgments}

This research is supported by the Chinese National Natural Science Foundation (No. 51522907, No. 51279208) and the Research Fund of the State Key Laboratory of Simulation and Regulation of Water Cycle in River Basin, China Institute of Water Resources and Hydropower Research (No. 2016ZY02).

\section{Reference}

[1]Griebler C, Stein H, Kellermann C, et al. Ecological assessment of groundwater ecosystems Vision or illusion?[J]. Ecological Engineering, 2010, 36(9):1174-1190.

[2]Gibert J, Griebler C, Gunatilaka A, et al. Incorporating ecological perspectives in European groundwater management policy[J]. Environmental Conservation, 2004, 31(3):185-189.

[3]Aryafar A, Yousefi S, Ardejani F D. The weight of interaction of mining activities: groundwater in environmental impact assessment using fuzzy analytical hierarchy process (FAHP)[J]. Environmental Earth Sciences, 2013, 68(8):2313-2324.

[4]Wada Y, Van Beek L P H, Van Kempen C M, et al. Global depletion of groundwater resources[J]. Geophysical Research Letters, 2010, 37(20):114-122.

[5]Mi L, Xiao H, Zhang J, et al. Evolution of the groundwater system under the impacts of human activities in middle reaches of Heihe River Basin (Northwest China) from 1985 to 2013[J]. Hydrogeology Journal, 2016, 24(4):971-986.

[6]Changnon S A, Huff F A, Hsu C F. Relations between Precipitation and Shallow Groundwater in Illinois.[J]. Journal of Climate, 2009, 1(1):1239-1250.

[7]Smerdon B D, Mendoza C A, Devito K J. Influence of subhumid climate and water table depth on groundwater recharge in shallow outwash aquifers[J]. Water Resources Research, 2008, 44(8).

[8]Zhou J, Xin L I, Wang G X, et al. The Spatio-temporal Variation Analysis of Groundwater and Response to Land-use Change in the Middle Reaches of the Heihe River Basin[J]. Journal of Natural Resources, 2009, 24(3):498-506.

[9]Qi X, Yang L, Han Y, et al. Cross Wavelet Analysis of Groundwater Level Regimes and Precipitation-Groundwater Level Regime in Ji'nan Spring Region[J]. Advances in Earth Science, 2012, 27(9):969-978.

[10]Valiaho, Hannu. A Procedure for Stepwise Regression Analysis[M]. Akademie, 1976. 